\title{
Políticas Públicas no Setor de Turismo ${ }^{1}$
}

\author{
Cássio Avelino S. Pereira
}

RESUMO: Analisa a origem c apresenta algumas razōes para se produzir políticas públicas de turismo, a partir da necessidade de se estabelecer normas e regras para definição do papel dos diversos atores que compōem o setor. Ênfase é dada nas idiossincrasias do caso brasileiro, especialmente no que concerne à dicotomia verticalização versus horizontalização da Política Nacional de Turismo.

PALAVRAS-CHAVE: turismo e política, políticas públicas de turismo, papel dos agentes públicos e privados, política nacional de turismo, Brasil.

ABSTRACT: It analyzes the origin and it presents some reasons to produce public politics of tourism, starting from the need to settle down norms and rulesfor definition of the paper of the several actors that compose the section. Emphasis is given in the idiosyncrasies of the Brazilian case, especially in what it concerns the vertical $x$ horizontal dicotomy of the national politics of tourism.

KEYWORDS: tourism and politics, politics publics, the actors' of the section of tourism paper, national politics of tourism, Brazil.

1. Este artigo é uma adaptação do primeiro capítulo da dissertação de Mestrado em Ciência Política intitulada. A

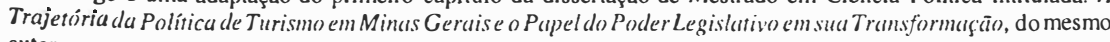
autor.

¿. Mestre em Ciência Política. Professor do Curso de Turismo, Ambiente e Sustentabilidade do $28^{\circ}$ Programa de PósGraduação Lıto Senısu da Pontifícia Universidade Católica de Minas Gerais. Pesquisador e Consultor do Centro de Pesquisa e Planejamento do Turismo - CPTUR.

End.: Caixa Postal 3.348 - 30140-970 - Belo Horizonte-MG - Brasil. E-mail: cptur@cptur.com.br 


\section{Introduçāo}

Os antecedentes das políticas públicas remontam os anos 40 c 50 nos EUA, após a Segunda Guerra Mundial e surgem com a preocupação da ocorrência de reversão do crescimento cconômico, uma vez que a economia de guerra estava sendo desmontada. Também estão associados ao reconhecimento do aumento da intervenção do Estado, desde a experiência do New Deal americano. No período postcrior, com ênfase especial a partir dos anos 60 , surgiu na agenda pública a necessidade de avaliar e discutir o que o Estado e o governo fazem através dos programas, projetos e políticas. Na origem das políticas públicas "cncontra-se um ideal construído por Stuart Mill de como melhorar a ação do governo para que elc aumente o bem estar dos indivíduos" (Tapia, 1998).

No campo disciplinar, a partir da ciência política em cspecial e da ciência social no sentido mais amplo, o nascimento das políticas públicas está relacionado à tentativa de gerar conhecimento aplicável às açõcs práticas dos governos, com ênfase na preocupação com a qualidade e eficácia da intervenção pública. Apcsar do conceito de política pública scr palco de muitas controvérsias, cstando distante de um consenso entre os estudiosos desse tema, será adotado nesse trabalho aquele que se baseia nas ações govcrnamentais que têm instilucionalidadc, ou scja, amparadas legalmente por programas, projetos, planos, metas e orçamento.

A consolidação de políticas públicas deve ser a manifestação primeira de uma conscientização governamental para a importância do turismocomo instrumento de crescimento econômico, geração de renda e melhoria da qualidade de vida da população. O turismo, dentro do seu amplo espectro e contex to, não é uma atividade que passa ao largo das transformações do mundo do trabalho e das necessidades da sociedade contemporânea, tampouco da globalização e da restruturação das atividades econômicas e produtivas.

Nessa perspectiva, esse trabalho aponta algumas razões para se produzir políticas públicas de turismo, a partir da necessidade de se estabelecer normas e regras para definição do papel, tanto do Poder Público quanto dos diversos atores privados relacionados ao setor. A varicdade de segmentos, atividades e interesses envolvidos no turismo e seu vínculo cada vez mais estreito com os recursos naturais, econômicos, culturais e históricos, evidenciam de um lado, que a forma do governo tratá-lo deve levar em conta essas fortes interfaces c, por outro, é fundamental que haja maior interação entre as atividades dos diversos grupos e setores da sociedade envolvidos com o turismo. Assim, o primeiro tópico é uma tentativa de reconstituir o processo que originou a socialização do turismo e a necessidade de produção de políticas públicas para o setor, enfatizando o difícil encargo de sua realização e, conseqüentemente, da planificação do turismo. Para ilustrar a discussão, serão abordadas as idiossincrasias do caso brasileiro com relação à política nacional de turismo, para que possam ficar mais claras as bases $\mathrm{cm}$ que foram apoiadas as vertentes estruturais que norteiam a política de turismo no Brasil.

\section{Produção das Políticas Públicas de Turismo}

A socialização do fenômeno do turismo em nível mundial guarda relação direta, de um lado, com o processo correspondente à fragmentação e ampliação da esfera de atuação do Estado e do outro, a sua relação com a sociedade. De maneira paradoxal, o crescimento do Estado no século XX, no seu aspecto quantitativo respondeu, em alguma medida, às alterações qualitativas de sua relação com a sociedade.

O papel e a organização do Estado em um determinado momento histórico pode ser compreendido, por um lado, em termos da definição de bens públicos e, por outro, em funçãoda forma de ofertadessesbens. Em sua delimitação mais restrita os bens públicos seriam circunscritos apenas à defesa externa eà ordem jurídica e institucional, abrangendo as garantias individuais, os direitos civis e políticos e o arcabouço normativo das atividades econômicas, entre outros. Em sua acepção ampliada os bens públicos englobam, além dos anteriores, os bens e serviços que a sociedade define como direitos do cidadão, por exemplo, educação, saúde, infra-estrutura, saneamento, lazer, turismo, etc. Embora o conceito tradicional de bem público o defina como aquele que não pode ser apropriado individualmente, sabemos que em cada situação concreta a maior ou menor amplitude desses bens depende de um pacto social e politico (Azevedo e Andrade, 1997; Azevedo, 1998).

Fundamentalmente, ocorreu uma tendência crescente de diversificação e complexidade do processo de organização da sociedade nas maneiras mais diversas possíveis, dos partidos políticos às entidades de classe, sindicatos, movimentos sociais, enfim, associações vinculadas a diversos interesses. Basicamente, este processo de diferenciação e de organização da sociedade correspondeu, de certa forma, ao movimento de expansão do Estado. A experiência do Welfare State, em última análise, é um processo que alarga a intervenção do Estado para atender a demandas colocadas pela sociedade. Nesse sentido, o crescimento quantitativo do Estado corresponde a uma mudança qualitativa na sua relação com a sociedade. Mais concretamente, corresponde a um processo pelo qual as demandas da sociedade dirigidas ao Estado se tornam cada vez mais específicas. O processo de consolidação do Welfare State é, na verdade, também um processo de institucionalização de áreas de intervenção pública, como na saúde, habitação, saneamento, transportes, comunicação, entre outras ${ }^{3}$, ocorrido no período posterior à Segunda Guerra Mundial.

Remonta também nesse período a origem das políticas públicas de turismo, marcada pela regulação do trabalho, da limitação do seu tempo, das férias remuneradas, da aposentadoria, da evolução dos transportes, da comunicação, além de outras conquistas da sociedade moderna. O turismo envol ve um elenco de atividades

\footnotetext{
3. Para análise do Weltare State ver, entre outros, o clássico trabalho de PRZEWORSK (1989).
} 
distribuídas por toda a cadeia cconômica e requer investimentos prévios em infraestrutura básica de apoio, como rodovias, aeroportos, saneamento, cducação, preservação ambiental, do patrimônio histórico e cultural, entre outros; c em serviços, como transportes, hotelaria, alimentação, atrações, agenciamento, recep tivos, marketing, etc. Portanto, produz efeitos multiplicadores sobre diversos segmentos econômicos, sociais, culturais, etc. (Becker, 1996:182-3; Angeli, 1991:47-8; Paiva, 1995:29)

Há de se considerar, também, os "efeitos perversos" advindos do fenômeno turístico. Os empregos gerados pelo setor caracterizam-se por sua freqüentc ligação como setorinformal, apresentando muitas vezes precariedades, como a sazonalidade, o absenteísmo, subqualificação, etc. O turismo pode gerar efeitos sociais bastantc temidos, como a aculturação, a prostituição, entrc outros, e impactos ambientais excessivamente predatórios. Além disso, é capaz de provocar a aceleração do processo inflacionário, quando a população flutuante aumenta a demanda por bens e serviços, em contrapartida aos empresários e comerciantes que elevam os preços na busca do lucro rápido. Contribui para a remessa de divisas estrangeiras utilizadas para importação de equipamentos e produtos exigidos pelos visitantes estrangeiros em países frágeis e pouco diversificados economicamente. A falta de legislação adequada pode permitir o uso do solo turístico de forma especulativa, favorecendo determinados grupos econômicos e a conseqüente expulsão das populações nativas, principalmente as de baixa renda (Cazes, 1996:80-1; Paiva, 1995:47-9).

O turismo é peculiar pelo fato de ser um setor fragmentado, que envolve muitos segmentos e negócios, e não apenas um produto que possa competir internacionalmente. Isto significa que o modo pelo qual o governo deve abordá-lo é especialmente importante se comparado a outros setores (Bennett, 1994:31). A política de turismo é a forma na qual o Poder Público intervém no setor. Essa é uma tarefa dispendiosa e os governos devem se conscientizar dos riscos e desafios envolvidos. Talvez, a principal vantagem do envolvimento do Estado seja evitar o desenvolvimento desenfreado, motivado unicamente pelo lucro por parte das empresas, o que pode ser prejudicial para o futuro do turismo no país como um todo (Abdel-Wahab, 1974:32). Em virtude da variedade de segmentos e interesses envolvidos, a participação do Estado na produção de políticas públicas de turismo tem se mostrado fundamental.

A principal justificativa para a intervenção do Estado, principalmente em países subdesenvolvidos, se baseia numa visão de que ela se faz necessária nos estágios iniciais de desenvolvimento do turismo em conseqüência do pouco background, capital e ausência de talentos. Argüi-se também que a ação do governo é necessária para abrir novas áreas para o turismo, onde os riscos são muito altos para o setor privado (Bennett, 1994:31). Nessa perspectiva, os planejamentos turísticos realizam uma arbitragem contrastante, derivada dos interesses particulares ou de grupos sociais de pressão e do interesse público e coletivo. A localização de um pólo turístico implicará, forçosamentc, a reavaliação da propriedade fundiária na zona de propagação da instalação turística. Isso desencadeará, obviamente, uma série de conflitos. O problema que surgeérelativo à realização da política de turismo, ou seja, a quem estará entregue a formulação e o difícil encargo da planificação turística (Sessa, 1983:139-40)

A prontidão para a tomada de decisões é essencial ao turismo, visto a suscetibilidade do fenômeno turístico e a necessidade de equilibrar suas múltiplas influências, algumas vezes contraditórias e intervenientes. O meio utilizado para equacionar as decisões é o interior do sistema da Organização Nacional de Turismo, organismo supremo do setor, que tem como função formular, orientar c executar a política turística geral do país (Abdel-Wahab, 1974:21). O lugar do turismo na estruturação administrativa do setor público dependerá, em definitivo, da oricntação que o governo de cada país der a este setor. Há uma tendência acentuada para que, na mudança do governo de um país, seja modificada também a orientação do turismo e sua posição hierárquica na administração pública. Isso provoca alterações na chamada organização institucional do setor (Beni, 1991:19).

Não há padronização da estrutura turística oficial (ministério, departamento, comissão, diretoria, conselho, instituto, corporação, entre outras). Cada país se organiza a partir de sua própria realidade e do grau de importância do setor para o governo. A estrutura do órgão oficial de turismo varia de acordo com a forma constitucional de governo. Quando um organismo nacional de turismo adota a forma de entidade oficial, esta pode ser através de um organismo centralizado ou estatal, criado pelo próprio Estado dentro de sua estrutura administrativa, podendo ocupar posições e hierarquias na estrutura organizacional. Também sob a forma de organismos descentralizados ou mistos, constituídos pelo Estado através de lei com personalidade jurídica, autonomia técnica e administrativa, embora mantenham vínculos de subordinação a um Ministério ou Secretaria de Estado. E ainda através de organismos privados ou não-governamentais, sem fïns lucrativos, na forma de uma associação ou fundação, organizados em todos os níveis (nacional, regional e local). Estes tipos de organismos são nitidamente operacionais e executam as políticas de turismo adotadas pelo Estado através do órgão competente (AbdelWahab, 1974:18; Beni, 1991: 19-21; Castelli, 1986:73).

Ao invés de um órgão governamental de turismo, existem experiências concretas em alguns países, como a Noruega, Dinamarca e Japão onde órgãos nãogovernamentais são reconhecidos pelo governo como planejadores do setor, respaldados pelas autoridades públicas e empresas privadas. Algumas organizações têm participação no fomento ou coordenação ativa no desenvolvimento e na promoção do turismo do país, da região ou da localidade (Abdcl-Wahab, 1974:18-9).

A existência de um órgão central de turismo e de organizações periféricas em diferentes regiões ou localidades e conselhos ou comitês interministeriais deve servir para que um suplemente e ajude o outro e não para que eles se sobreponham. O desenvolvimento do turismo demanda interfaces com outras políticas recorrentes $\mathrm{c}$ complementares, tornando-se necessário um intenso trabalho de coordenação com outros setores. Portanto, as políticas de turismo devem estar coordenadas com as demais políticas setoriais afins do país (Abdel-Wahab, 1992:748). Um outro aspecto a ser levantado converge para as relações entre os atores públicos e privados na formulação e implementação da política de turismo. 
A política nacional de turismo ć (ou pelo menos deveria ser) o elo integrador entre a csfera governamental representada pelos segmentos oficiais do sistema e os beneficiários e usuários dessa política. No seu interior encontram-sc as diretrizes ou políticas básicas que expressam os caminhos para atingir os objetivos nacionais para o turismo. O desdobramento dessas políticas básicas em programas de execução acompanhados da indicação dos projetos, cnvolve os instrumentos do planejamento necessários à implementação do setor (Nogueira, 1983:168).

Todavia, o Poder Público pode desestimular a iniciativa privada ao criar instrumentos legais sem captar a fundo a essência da atividade turística. Estes instrumentos, em face da sua multiplicidade, podem criar dificuldades operacionais para as empresas que atuam no turismo. Sendo um setor novo e dinâmico, o turismo precisa ser constantemente analisado e avaliado para reformulação de suas políticas públicas.

O turismo se desenvolve e funciona dentro de uma estrutura legal que pode ser dividida em duas partes. A primeira é alegislação dos setores que possuem um maior trade offcom o turismo e que normalmente não é pensada como tendo resultados turisticos, mas que afeta inevitavelmente as operações nesse setor. A mais comum inclui regulamentações no investimento, comércio, competição, propriedade, propaganda, proteção ambiental e uso da terra e vários aspectos do mercado de trabalho, como salários mínimos, carga horária, condições de trabalho, oportunidadesiguaise restrições ao trabalho estrangeiro, interferindo, dessa forma, na oferta e preço do trabalho. A segunda parte é a legislaçāo turistica stricto sensu - as leis e regulamentos direcionados ao setor e que lidam com a operação e gerenciamento de empreendimentos turisticos, como as regulamentações no transporte e operações de serviços de viagens, taxas especiais de embarque e desembarque de passageiros, incentivos financeiros e fiscais, uso e ocupação do solo e outros recursos naturais para desenvolvimento e geração de demanda de turismo, entre outros (Liu, 1994:24).

Dessa forma, é inconcebível que o setor privado não participe desse processo. Existe quantidade considerável de decisões públicas tomadas pelo setor hoteleiro, de transporte e outros que operacionalizam o setor turístico, em vista de decisões não tomadas pelo governo e dos vazios da legislação (Nogueira, 1983:168-9). Há um corpo crescente de opinião que sugere que o envolvimento do setor privado não deva ser limitado ao fornecimento de serviços turísticos, mas também estar envolvido com o planejamento e a formulação de políticas de turismo. A importância de arranjos envolvendo a comunidade anfitriã em parcerias com os governos locais em políticas de turismo também tem sido muito divulgada(Jenkins, 1994; Long, 1994)

Atualmente, há uma tendência do Estado em garantir a regulação para fïns de utilização dos atrativos naturais, culturais, históricos e outros. A extensão de tal controle deveria ser acordada entre os interesses turísticos públicos, privados e pelos usuários e beneficiários dos serviços, para que os conflitos de interesses pudessem ser atenuados. Torna-se imperativa a participação ativa, consciente, deliberada e decisiva da comunidade no processo de formulação e implementação da política pública de turismo. Institucionalmente, a comunidade deverá estar representada pelos líderes das diversas categorias que a compõem, como os empresários, trabalhadores, autoridades locais, regionais, estaduais, meios de comunicação, organizações não governamentais, entre outros (Nogueira, 1987:52).

Os anos 90 são marcados pela emergência de termos o turismo verde ou ecoturismo, turismo responsável, solidário, cultural, todos ligados à noção de qualidade de vida, o que reflete o aumento do interesse nos impactos não econômicos (ebenefícios)advindos dosetor. Há uma percepção incipiente de que a sustentabilidade do turismo não se baseia apenas em critérios econômicos, mas deve também tornarse adequado às necessidades das comunidades anfitriãs. As políticas de turismo estão começando a se tornar mais sensíveis às necessidades da população local e estão reconhecendo também que nem todos os tipos de turismo são necessariamente benéficos. Isto significa que, dentro da escala de desenvolvimento turístico de cada país, maior ênfase está sendo dada à oferta local de atrativos e roteiros segmentados, colocando o turista em contato com a natureza e a comunidade local. A idéia de que o turismo possa simplesmente ser imposto a um país ou região é hoje muito rejeitada em favor de uma abordagem mais equilibrada para as necessidades de visitantes e anfitriões (Jenkins, 1994:5-6).

Há um consenso de que um importante papel do governo seja a responsabilidade pela educação, conscientização e treinamento em todas as atividades que envolvam o turismo. A educação, em todos osníveis, é uma ferramenta indispensável para implementar a consciência e a qualificação do turismo, aumentando, conseqüentemente, a produtividade do setor. Ao assumir a liderança, o governo poderia oferecer as facilidades necessárias para que a profissionalização fosse efetivada em cooperação com as preocupações turísticas já abordadas.

A intervenção do Estado na criação e no gerenciamento direto da superestrutura turística tem sido desaprovada por governos em economias de mercado aberto. A alocação de recursos financeiros para o setor de turismo pelo orçamento do governo tem sido basicamente para infra-estrutura, que é multissetorial em dimensão, já que beneficia quase todos os outros setores. De outro modo, despesas diretas do governo com o turismo tendem a cobrir custeio administrativo, pesquisa marketing. Geralmente, as quantias envolvidas são muito pequenas em relação ao orçamento total do governo e são encolhidas pelas alocações a outros setores (Bennett, 1994:34). No entanto, há várias formas pelas quais o governo pode promover investimentos diretamente no turismo.

A estabilidade econômica é requisito básico para estimular investimentos e, para atraí-lo,é precisoser internacionalmente competitivo (Abdel-Wahab, 1992:751). Em muitos países em desenvolvimento o mercado de capital é pequeno e sua mobilização é fraca. O recurso financeiro pode estar disponível, mas não há mecanismos para inserir o capital de grupos econômicos dentro de um consórcio suficientementegrande para prover empreendimentos turísticos. O capital estrangei 
CNTur. Por sua vez, o regime jurídico do turismo no plano federal se viu contestado e posteriormente modificado, transformando a EMBRATUR de empresa pública a autarquia, por conseqüência, alterando sua denominação para Instituto Brasileiro de Turismo. Dessa forma, além do acervo documental, as atribuições e competências do extinto CNTur são transferidos para a EMBRATUR, que passa a ser vinculada à Secretaria de Desenvolvimento Regional, com sede e foro no Distrito Federal (Beni, 1991:95-106; Ferraz, 1992:37-43).

Embora essa iniciativa tenha conferido ao turismo maior centralização na esfera do Poder Público, o setor continuava a padecer da falta de institucionalização de uma política nacional que integrasse as ações dos órgãos oficias e da iniciativa privada. Contudo, esse processo levou à proposição de planos e programas de privatização e desregulamentação do setor, acentuando o prosseguimento de decisões pontuais e isoladas (Beni, 1991:104).

Até o final dos anos 80 , considerava-se que a melhor forma para organização da política de turismo no país seria através do estabelecimento de uma cúpula do setor, composta pelo Sistema Nacional de Turismo (EMBRATUR, CNTur e o Ministério da Indústria e do Comércio). Esperava-se que essa centralização no planejamento e coordenação, acompanhada da verticalização na execução da política, dos planos, programas e projetos trouxesse maior eficiência na utilização dos recursos, delimitação das áreas de subordinação ao órgão central e, por fím, redução dos conflitosnos processos decisórios. Entretanto, as decisões que norteavam a política nacional de turismo eram tomadas dentro de uma estrutura organizacional com ausência de representatividade, já que a iniciativa privada era minoria e as diretrizes traçadas sem a participação dos representantes dos governos estaduais e municipais, bem como dos usuários e beneficiários dessa política (Nogueira, 1992:103-4).

A verticalização da política nacional de turismo, orientada sob a égide da hierarquização, centralização e subordinação ao Sistema Nacional de Turismo, produziu ações paralelas e desconexas, não integralizando em sua base uma política, um programa ou plano que definisse parâmetros para a execução de ações planejadas e associadas. As determinações em relação às prioridades do turismo eram feitas por

uma tecnoburocracia através de memorandos e minutas de projetos de lei que definiam todos os planos e programas, a concessão do financiamento estatal e dos incentivos fiscais, colocando a atividade turisticaà mercê dos interesses organizacionais e pessoais dos formuladores (Nogueira, 1992:105-6).

Desse modo, a articulação entre os diversos agentes intervenientes do processo de desenvolvimento da atividade turística eram descoordenadas ou inexistentes, acentuando as dificuldades de conciliação entre o plano institucional e o modelo de gestão com o processo normativo do turismo.

Conforme o resultado da pesquisa realizada em 1991 pelo professor Mário
Beni sobre o desempenho operacional do Sistema Nacional de Turismo, as principais dificuldades conjuntas das instituições públicas na ordenação e promoção do setor concentram-se na indefinição de uma política nacional de turismo que normatize a sua ordem institucional e gestão, caracterizada como um dos maiores entraves à definição de planos e programas de ação no âmbito das organizações. Outras dificuldades constatadas foram a falta de integração e coordenação entre os organismos oficiais de turismo em todos os níveis, a inexistência de uma ação intersetoria no desenvolvimento do turismo e a acentuada modificação no processo diretivo em cada mudança de governo, acarretando descontinuidade administrativa e indefiniç̧ão de prioridades políticas para o setor. Foram apontadas também a carência de mãode-obra qualificada e especializada, com a conseqüente ausência de pesquisas científicas necessárias ao conhecimento do fenômeno turístico, bem como a escassez de recursos financeiros para o exercício de uma administração pública mais profissional, o que reflete de maneira negativa sobre o grau de motivação de todos os níveis funcionais do setor (Beni, 1991:161-99). Denota-se, portanto, que esse conjunto de condições e situações constituem os empecilhos que emperram e desagregam o pleno funcionamento do processo de desenvolvimento do turismo.

Em 1994, após o tempestuoso governo Collor e o longo período de verticalização ao qual foi submetida a política de turismo no Brasil, o então presidente Itamar Franco inicia o processo de construção de uma diretriz nacional para a política de turismo no país. Nessa oportunidade, é instituído o Plano Nacional de Municipalização do Turismo (PNMT), instrumento legal e referencial para todos os segmentos que atuam com o turismo no país e que tem como público-alvo o município. Como num efeito dominó, o turismo municipal influi sobre o desempenho do turismo estadual, que por sua vez determina a eficácia do turismo nacional e a conseqüente competitividade internacional do produto turístico brasileiro, através da busca da qualidade na prestação de serviços e no correto gerenciamento dos recursos naturais e culturais por parte de todos os atores envolvidos neste processo, quer sejam eles públicos ou privados.

Com esse enfoque, inicia-se a horizontalização das diretrizes e ações para a política de turismo no Brasil, tendo como referência a integração de todos os atores intervenientes no setor e agindo na base, que é o município. Como atividade que se desenvolve graças aos atrativos localizados, utilizando serviços e gerando impostos primordialmente municipais, nada mais adequado que concentrar os processos de planejamento e de gerenciamento no município, procurando desenvolver ao máximo a comunidade local, vinculando-a aos projetos a serem implantados. Nesse sentido, a municipalização do turismo tem como objetivo produzir benefícios sociais, culturais, econômicos e ambientais, dentro de um contexto planejado nos níveis local, estadual, regional, nacional e até internacional, gerido com a participação e envolvimento da população residente nos municípios, de modo a conciliar a coordenação de ações segmentadas com a eliminação de ações paralelas no desenvolvimento do turismo (EMBRATUR, 1997).

Dentro dessa perspectiva, ressalta-se que o governo do Presidente Fernando Henrique Cardoso dá prosseguimento ao processo de horizontalização da política e 
seus programas e projetos envolvendo o turismo, afastando o risco da interrupção desses procedimentos em sua fase de implantação. Com isso, a EMBRATUR vem se reestruturando a partir da descentralização na gestão turística, através do projeto de fortalecimento dos órgãos estaduais e municipais de turismo, buscando a reconversão da ação fiscalizadora em uma atividade orientadora aos empresários e preventiva de infrações. No nível da execução, a orientação referencial é para o setor privado, resguardando os programas específicos e a capacidade de iniciativa das comunidades, respeitando as peculiaridades municipais, regionais e estaduais (Ministério da Indústria, do Comércio..., 1995).

A relação entre União e Estados envolvendo o setor se dá, principalmente, através da delegação de competências da EMBRATUR aos órgãos oficiais de turismo, para a execução de atribuições no âmbito de cada unidade da federação, incrementando a assistência técnica a esses organismos. O papel do Estado junto aos municípios é semelhante ao desenvolvido pela EMBRATUR junto aos Estados, ou seja, é importante que haja uma política estadual sólida que possa dotar os municípios de condições técnicas e organizacionais para promover o desenvolvimento de sua atividade turística.

Com o propósito de incentivar os municípios a adotarem suas próprias políticas, é necessário adequar a política estadual às suas potencialidades locais cabendo ao Estado propiciar oportunidades para o engajamento dos municípios no PNMT. Com efeito, possibilita-se o desenvolvimento de políticas regionais de turismo, baseadas na integração de destinos ou circuitos turísticos, formando assim consórcios intermunicipais de turismo.

Dessa forma, o Poder Público pode e deve viabilizar outras formas de incentivo, como a redução de impostos para novos empreendimentos no setor, isenção temporária de obrigações fiscais, empenho de um percentual da arrecadação parainvestimentos no setor turístico, entre outros. Nessa perspectiva, o financiamento e investimento da política de turismo no Brasil precisa deixar de privilegiar o grande investidor e levar em consideração também o micro, pequeno e médio investidor local, para que sejam assegurados os benefícios do turismo para a comunidade anfitriã. O modelo das grandes construções e complexos turísticos, que assolam o meio ambiente e atraem turistas que não consomem a cultura e os produtos locais, está fadado à extinção.

\section{Consideraçōes Finais}

A obtenção de uma política integrada do turismo no âmbito federal, estadual e municipal deve ser matéria de responsabilidade de todo o segmento do turismo quer seja público ou privado. Assim, a política nacional de turismo terá sua efetividade e legitimidade ampliada na medida em que for apoiada na mais larga base representativa dos interesses da sociedade, garantindo seu desenvolvimento e minimizando seus efeitos perversos. Além da participação do Estado, é fundamental que haja o envolvimento dos usuários e beneficiários do setor na produção e avaliação de políticas públicas de turismo (Pereira, 1999b)

O Estado vinha atuando no turismo de forma direta como fïnanciador “empreendedor", passando, pau

atividades sob sua responsabilidade direta e a propor politıcas de corte mals regulatório e descentralizador. Hoje o cenário é de um Estado que está redefinindo seu papel, tentando agir mais como re

elemento central investimentos gerais e de infra-estrutura somente com recursos públicos é uma prática em desuso.

Atualmente, encontra-se em andamento um processo que pretende ajustar e adequar o setor através de políticas regulatórias, aspecto esse em que, de forma geral, ostado brasileiro foi sempre muito frágil. Essa dificuldade pode se justificar, em parte, pelo fato de ser muito difícil o Estado operar junto à iniciativa privada e, portanto, se autoregular. Somente agora nos anos 90 é que tem sido efetivado, dentro da reforma do Estado, seu papel de regulador (Dinize Azevedo, 1997). A fragilidade na regulação pode ser apontada, inclusive, como uma das falhas estruturais dos países em desenvolvimento.

O fato é que o esgotamento do modelo de Estado desenvolvimentista nos anos 80 foi sentido muito mais rapidamente no turismo do que em outros setores. Enquanto o processo de privatização dos setores de siderurgia, energia, telecomunicação e outros aconteceram já nos anos 90 , ainda na década de 80 , boa parte dos Estados brasileiros e a união começaram a vender ou arrendar seus hotéis, companhias aéreas, etc. Mesmo com dificuldades instrumentais para privatizar, a idéia de que a operacionalização de um setor poderia caber eminentemente à iniciativa privada ficou clara mais cedo no turismo do que em outros setores. Tanto que não houve resistência alguma às tentativas de privatização dos equipamentos turísticos do Estado. Tais ações podem não ter alcançado os resultados esperados, mas devido a outros fatores, como o processo com que foram conduzidas e por problemas institucionais.

O processo de reforma do Estado tem perpassado pelo turismo de uma forma diferente e específica. Não se tem notícia de outro setor em que essa transformação tenha passado tão desapercebido pela opinião pública. Diferente dos demais setores que enfrentaram essa experiência da privatização, no turismo, apesar do governo ainda não ter conseguido avançar muito, a decisão em favor de privatizar ocorreu sem nenhum tipo de manifestação pública contrária. Nesse sentido, é importante ressaltar, mais uma vez, que a decisão de privatizar ocorreu no turismo antes da onda da reforma do Estado nos anos 90. Portanto, há nesse setor um ambiente mais favorável para o consenso em relação à sua privatização, já que não incita nenhum debate público ou movimento popular contrário.

Enfim, o Estado deve optar por um menor controle operacional em troca de maior poder sobre a regulação, as metas e os resultados no turismo, cedendo parte de seu poder operativo à iniciativa privada e à comunidade. Todavia, ainda é necessário avançar em muitos procedimentos políticos, institucionais e normativos paraconvergir as açõese diretrizes para o setor, nabuscade uma gestão horizontalizada 
e integrada com a base de sustentação do turismo que é o município. O desafio pode ser traduzido na busca de uma forma de conciliar as dimensões normativas c institucionais do turismo com a gestão da política, de modo que haja melhor distribuição dos benefícios sociais, econômicos, políticos, entre outros, aumentando a qualidade dos serviços e o bem-estar dos visitantes e da comunidade anfitriã.

\section{Referências Bibliográficas}

ABDEL-WAHAB, SalahE. 1974. Elementsof State Policy on Tourism - with special emphusis on developing countries. Cornell USA.

1992. Government's Role in Strategic Planning for Tourism. USA. In: KHAN, Mahmood A.; OLSEN, Michael D.; VAR, T. (eds.). VNR's Encyclopedia of hospitulity and tourism. USA: Van Nostrand Reinhold.

ANGELI, Margarita N. Barretto. 1991. Planejamento e Organizaçüo em Turismo. São Paulo: Papirus.

AZEVEDO, Sérgio de e ANDRADE, Luis Aureliano G. 1997. A reforma do Estado e a çuestão federalista: retlexōes sobre a proposta Bresser Pereira. In: DINIZ, Eli e AZEVEDO, Sérgio de (orgs.). Reforma do Estudo e Democracia no Brasil. Brasilia: UNB/ENAP.

AZEVEDO, Sérgio de. 1998. Reforma do Estadoe Mudanças Institucionais no Brasil: variáveis exógenas e endógenas. In:SEMINARIOINTERNACIONALAREFORMADA ADMINISTRACAOPUBLICANOBRASIL:POSSIBI LIDADES E OBSTACULOS. Recife: Fundação Joaquim Nabuco/ Escola de Governo do Estado de Pernambuco. BECKER, Bertha. 1996. Políticas e planejamento do turismo no Brasil. In: YÁZIGI, Eduardo et al. (orgs.). Turismo: e.spaç̧o, paisagem e cultura. São Paulo: Hucitec.

BENI, Mario Carlos. 1991. Análise do Desempenho do Sistema Nacional de Turismo Instituido na Administraşäo Pública. Tese (Livre-Docência) - Escola de Comunicaçōes e Artes Universidade de São Paulo

BENNETY, O. 1994. Financing for tourism projects in developing countries. In: SEATON, A. V. et al. (eds.). Tourism: the state of the art. England: Wiley Publishers.

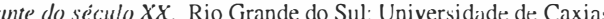
do Sul, EDUNISUL.

CALCANTI, Keila Brandão e PAIVA, Maria das Graças de M. 1993. Turismo Urbano e Intervenção do Estado. Turismo em Ancilise, São Paulo, v 4, n. I maio

CAZES, George 1996. Turismo e subdesenvolvimento: tendências recentes, In: RODRIGUES, Adyr A Balastrer (Org.). Turismo e Geografia: reflexōesteóricas e enfoques regionais. São Paulo: HUCITEC.

DINIZ, Eli e AZEVEDO, Sérgio de. (orgs). 1997. Reforma do Estudo e Democracia no Brasil. Brasília: UNB/ENAP. EMBRATUR .1977. Políitca Nacional de Turismo - Documento Preliminar. (mimeo).

1997. Diretrizes do Programa Nacional de Municipalizaḉăo do Turismo. Brasília. Elaborado pela Gerência de Programas Nacionais; Supervisão de Projetos de Descentralização.

ERRAZ, Joandre Antonio. 1992. Regime juridico do turismo. São Paulo: Papirus.

ENKINS, C. L. 1994. Tourism in developing countries: the privatisation issue. In: SEATON,A . V. et al. Tourism: the stute of the art. England: Wiley Editorial Offices.

U. Z.-H. 1994. Tourism development - a systems analysis. In: SEATON, A. V. et al. Tourism: the stute of the art. England: WileyPublishers.

. A. V. et al. Tourism: the state of the art. England: Wiley Publishers.

I995. Pollicu 1990 Prestestratégiase programas. Brasilia: EMBRATUR. Revis

Reviste de Administrusino

Públic 1987. O papel do turismo no desenvolvimento econômico e social do Bras

ica, Rio de Janeiro: Fundação Getulio Vagas, v. 21, n. 2, p. 37-54, abr.jun

- 1992. Política nacional de turismo: distorçôes e participacâa, In: Municipio y' turismo. España: Union Iberoamericana de Municipalistas. Cuadernos de documentacion e informacion municipal. $n^{\circ} 12$

PAIVA, Maria das Graças de Menezes V. 1995. Sociologia do Turismo. São Paulo: Papirus.

PEREIRA, Cássio Avelino S. 1999a. A trajetória da política de turismo em Minas Gerais eo papel do Poder Legislativo em sua transformação. Tese (Mestrado) Unversidade Federal de Minas Gerais. 1999b. Procedimentos para Avaliação de Políticas Públicas pelo Poder Legislativo-Estudo de caso da política
de turismo de Minas Gerais. Revista do Le gislatutivo, Belo Horizonte, n² 25, jan-mar. (Encarte)
PRZEWORSK, Adam. 1989. Capitulismo e Social-Democraciul. São Paulo: Companhia das Letras. SESSA, Alberto. 1983. Turismo e política de desenvolvimento. Rio Grande do Sul: UNIONTUR

列 Horizonte: Escola do Legislativo da Assembléia Legislativa de Minas Gerais. novembro.

\section{Recebido em 1711199}

Aprovado em 20/12/9 